\title{
Framing: Toward Clarification of a Fractured Paradigm
}

\author{
by Robert M. Entman, Northwestern University
}

In response to the proposition that communication lacks disciplinary status because of deficient core knowledge, I propose that we turn an ostensible weakness into a strength. We should identify our mission as bringing together insights and theories that would otherwise remain scattered in other disciplines. Because of the lack of interchange among the disciplines, hypotheses thoroughly discredited in one field may receive wide acceptance in another. Potential research paradigms remain fractured, with pieces here and there but no comprehensive statement to guide research. By bringing ideas together in one location, communication can aspire to become a master discipline that synthesizes related theories and concepts and exposes them to the most rigorous, comprehensive statement and exploration. Reaching this goal would require a more self-conscious determination by communication scholars to plumb other fields and feed back their studies to outside researchers. At the same time, such an enterprise would enhance the theoretical rigor of communication scholarship proper.

The idea of "framing" offers a case study of just the kind of scattered conceptualization I have identified. Despite its omnipresence across the social sciences and humanities, nowhere is there a general statement of framing theory that shows exactly how frames become embedded within and make themselves manifest in a text, or how framing influences thinking. Analysis of this concept suggests how the discipline of communication might contribute something unique: synthesizing a key concept's disparate uses, showing how they invariably involve communication, and constructing a coherent theory from them.

Whatever its specific use, the concept of framing consistently offers a way to describe the power of a communicating text. Analysis of frames illuminates the precise way in which influence over a human consciousness is exerted by the transfer (or communication) of information from

Robert M. Entman is an associate professor of communication studies, journalism, and political science and chair of the program in Communications, Media, and Public Policy at the Center for Urban Affairs and Policy Research at Northwestern University, Evanston, IL. He gratefully acknowledges the comments of students in his "Mass Communication and Democratic Theory" seminar, especially Andrew Rojecki.

Copyright (c) 1993 Journal of Communication 43(4), Autumn. 0021-9916/93/\$5.00 
one location-such as a speech, utterance, news report, or novel-to that consciousness. (A representative list of classic and recent citations would include: Edelman, 1993; Entman \& Rojecki, 1993; Fiske \& Taylor, 1991; Gamson, 1992; Goffman, 1974; Graber, 1988; Iyengar, 1991; Kahneman \& Tversky, 1984; Pan \& Kosicki, 1993; Riker, 1986; Snow \& Benford, 1988; Tuchman, 1978; White, 1987; Zaller, 1992.) A literature review suggests that framing is often defined casually, with much left to an assumed tacit understanding of reader and researcher. After all, the words frame, framing, and framework are common outside of formal scholarly discourse, and their connotation there is roughly the same. The goal here is to identify and make explicit common tendencies among the various uses of the terms and to suggest a more precise and universal understanding of them.

\section{Of Frames and Framing}

Framing essentially involves selection and salience. To frame is to select some aspects of a perceived reality and make them more salient in a communicating text, in such a way as to promote a particular problem definition, causal interpretation, moral evaluation, and/or treatment recommendation for the item described. Typically frames diagnose, evaluate, and prescribe, a point explored most thoroughly by Gamson (1992). An example is the "cold war" frame that dominated U.S. news of foreign affairs until recently. The cold war frame highlighted certain foreign events-say, civil wars-as problems, identified their source (communist rebels), offered moral judgments (atheistic aggression), and commended particular solutions (U.S. support for the other side).

Frames, then, define problems - determine what a causal agent is doing with what costs and benefits, usually measured in terms of common cultural values; diagnose causes-identify the forces creating the problem; make moral judgments-evaluate causal agents and their effects; and suggest remedies-offer and justify treatments for the problems and predict their likely effects. A single sentence may perform more than one of these four framing functions, although many sentences in a text may perform none of them. And a frame in any particular text may not necessarily include all four functions.

The cold war example also suggests that frames have at least four locations in the communication process: the communicator, the text, the receiver, and the culture. Communicators make conscious or unconscious framing judgments in deciding what to say, guided by frames (often called schemata) that organize their belief systems. The text contains frames, which are manifested by the presence or absence of certain keywords, stock phrases, stereotyped images, sources of information, and sentences that provide thematically reinforcing clusters of facts or judgments. The frames that guide the receiver's thinking and conclusion may or may not reflect the frames in the text and the framing intention of the 
communicator. The culture is the stock of commonly invoked frames; in fact, culture might be defined as the empirically demonstrable set of common frames exhibited in the discourse and thinking of most people in a social grouping. Framing in all four locations includes similar functions: selection and highlighting, and use of the highlighted elements to construct an argument about problems and their causation, evaluation, and/or solution.

\section{How Frames Work}

Frames highlight some bits of information about an item that is the subject of a communication, thereby elevating them in salience. The word salience itself needs to be defined: It means making a piece of information more noticeable, meaningful, or memorable to audiences. An increase in salience enhances the probability that receivers will perceive the information, discern meaning and thus process it, and store it in memory (see Fiske \& Taylor, 1991).

Texts can make bits of information more salient by placement or repetition, or by associating them with culturally familiar symbols. However, even a single unillustrated appearance of a notion in an obscure part of the text can be highly salient, if it comports with the existing schemata in a receiver's belief systems. By the same token, an idea emphasized in a text can be difficult for receivers to notice, interpret, or remember because of their existing schemata. For our purposes, schemata and closely related concepts such as categories, scripts, or stereotypes connote mentally stored clusters of ideas that guide individuals' processing of information (see, e.g., Graber, 1988). Because salience is a product of the interaction of texts and receivers, the presence of frames in the text, as detected by researchers, does not guarantee their influence in audience thinking (Entman, 1989; Graber, 1988).

Kahneman and Tversky (1984) offer perhaps the most widely cited recent example of the power of framing and the way it operates by selecting and highlighting some features of reality while omitting others. The authors asked experimental subjects the following:

Imagine that the U.S. is preparing for the outbreak of an unusual Asian disease, which is expected to kill 600 people. Two alternative programs to combat the disease have been proposed. Assume that the exact scientific estimates of the consequences of the programs are as follows: If Program $A$ is adopted, 200 people will be saved. If Program $B$ is adopted, there is a one-third probability that 600 people will be saved and a twothirds probability that no people will be saved. Which of the two programs would you favor? (1984, p. 343)

In this experiment, 72 percent of subjects chose Program A; 28 percent 
chose Program B. In the next experiment, identical options to treating the same described situation were offered, but framed in terms of likely deaths rather than likely lives saved: "If Program $\mathrm{C}$ is adopted, 400 people will die. If Program D is adopted, there is a one-third probability that nobody will die and a two-thirds probability that 600 people will die" (Kahneman \& Tversky, 1984, p. 343). The percentages choosing the options were reversed by the framing. Program $C$ was chosen by 22 percent, though its twin Program A was selected by 72 percent; and Program D garnered 78 percent, while the identical Program B received only 28 percent.

As this example vividly illustrates, the frame determines whether most people notice and how they understand and remember a problem, as well as how they evaluate and choose to act upon it. The notion of framing thus implies that the frame has a common effect on large portions of the receiving audience, though it is not likely to have a universal effect on all.

Kahneman and Tversky's experiments demonstrate that frames select and call attention to particular aspects of the reality described, which logically means that frames simultaneously direct attention away from other aspects. Most frames are defined by what they omit as well as include, and the omissions of potential problem definitions, explanations, evaluations, and recommendations may be as critical as the inclusions in guiding the audience.

Edelman highlights the way frames exert their power through the selective description and omission of the features of a situation:

The character, causes, and consequences of any phenomenon become radically different as changes are made in what is prominently displayed, what is repressed and especially in bow observations are classified. ... ITlbe social world is . . a kaleidoscope of potential realities, any of which can be readily evoked by altering the ways in which observations are framed and categorized. (1993, p. 232)

Receivers' responses are clearly affected if they perceive and process information about one interpretation and possess little or incommensurable data about alternatives. This is why exclusion of interpretations by frames is as significant to outcomes as inclusion.

Sniderman, Brody, and Tetlock (1991) provide a clear instance of the power of presence and absence in framing:

The effect of framing is to prime values differentially, establishing the salience of the one or the other. [Thus] . . a majority of the public supports the rights of persons with AIDS when the issue is framed in a survey questionl to accentuate civil liberties considerations-and supports ... mandatory testing when the issue is framed to accentuate public bealth considerations. (p. 52) 
The text of the survey question supplies most people with the considerations they use when they respond to the issue of AIDS testing (Zaller, 1992). Often a potential counterframing of the subject is mostly or wholly absent from a text, although, to use this instance, an audience member with a strong civil liberties philosophy might reject mandatory testing even if the poll framed AIDS strictly in public health terms.

\section{Frames in Political News}

This portrait of framing has important implications for political communication. Frames call attention to some aspects of reality while obscuring other elements, which might lead audiences to have different reactions. Politicians seeking support are thus compelled to compete with each other and with journalists over news frames (Entman, 1989; Riker, 1986). Framing in this light plays a major role in the exertion of political power, and the frame in a news text is really the imprint of power-it registers the identity of actors or interests that competed to dominate the text.

Reflecting the play of power and boundaries of discourse over an issue, many news texts exhibit homogeneous framing at one level of analysis, yet competing frames at another. Thus, in the pre-war debate over U.S. policy toward Iraq, there was a tacit consensus among U.S. elites not to argue for such options as negotiation between Iraq and Kuwait. The news frame included only two remedies, war now or sanctions now with war (likely) later, while problem definitions, causal analyses, and moral evaluations were homogeneous. Between the selected remedies, however, framing was contested by elites, and news coverage offered different sets of facts and evaluations. The Iraq example reveals that the power of news frames can be self-reinforcing. During the pre-war debate, any critique transcending the remedies inside the frame (war soon versus more time for sanctions) breached the bounds of acceptable discourse, hence was unlikely to influence policy. By conventional journalistic standards, such views were not newsworthy (Entman \& Page, in press). Unpublicized, the views could gain few adherents and generate little perceived or actual effect on public opinion, which meant elites felt no pressure to expand the frame so it included other treatments for Iraqi aggression, such as negotiation. Relatedly, Gamson (1992) observes that a frame can exert great social power when encoded in a term like affirmative action. Once a term is widely accepted, to use another is to risk that target audiences will perceive the communicator as lacking credibility-or will even fail to understand what the communicator is talking about. Thus the power of a frame can be as great as that of language itself.

\section{Benefits of a Consistent Concept of Framing}

An understanding of frames helps illuminate many empirical and normative controversies, most importantly because the concept of framing $\mathrm{di}$ - 
rects our attention to the details of just how a communicated text exerts its power. The example of mass communication explored here suggests how a common understanding might help constitute framing as a research paradigm. A research paradigm is defined here as a general theory that informs most scholarship on the operation and outcomes of any particular system of thought and action. The framing paradigm could be applied with similar benefits to the study of public opinion and voting behavior in political science; to cognitive studies in social psychology; or to class, gender, and race research in cultural studies and sociology, to name a few. Here are some illustrations of theoretical debates in the study of mass communication that would benefit from an explicit and common understanding of the concept of frames.

1. Audience autonomy. The concept of framing provides an operational definition for the notion of dominant meaning that is so central to debates about polysemy and audience independence in decoding media texts (Fiske, 1987). From a framing perspective, dominant meaning consists of the problem, causal, evaluative, and treatment interpretations with the highest probability of being noticed, processed, and accepted by the most people. To identify a meaning as dominant or preferred is to suggest a particular framing of the situation that is most heavily supported by the text and is congruent with the most common audience schemata.

A framing paradigm cautions researchers not to take fugitive components of the message and show how they might be interpreted in ways that oppose the dominant meaning. If the text frame emphasizes in a variety of mutually reinforcing ways that the glass is half full, the evidence of social science suggests that relatively few in the audience will conclude it is half empty. To argue that the polysemic properties of the message conduce to such counterframing, researchers must show that real-world audiences reframe the message, and that this reframing is not a by-product of the research conditions-for example, a focus group discussion in which one participant can lead the rest, or a highly suggestive interview protocol (Budd, Entman, \& Steinman, 1990).

Certainly people can recall their own facts, forge linkages not made explicitly in the text, or retrieve from memory a causal explanation or cure that is completely absent from the text. In essence, this is just what professors encourage their students to do habitually. But Zaller (1992), Kahneman and Tversky (1984), and Iyengar (1991), among others, suggest that on most matters of social or political interest, people are not generally so well-informed and cognitively active, and that framing therefore heavily influences their responses to communications, although Gamson (1992) describes conditions that can mitigate this influence.

2. Journalistic objectivity. Journalists may follow the rules for "objective" reporting and yet convey a dominant framing of the news text that prevents most audience members from making a balanced assessment of a situation. Now, because they lack a common understanding of framing, journalists frequently allow the most skillful media manipulators to im- 
pose their dominant frames on the news (Entman, 1989; Entman \& Page, in press; Entman \& Rojecki, 1993). If educated to understand the difference between including scattered oppositional facts and challenging a dominant frame, journalists might be better equipped to construct news that makes equally salient-equally accessible to the average, inattentive, and marginally informed audience-two or more interpretations of problems. This task would require a far more active and sophisticated role for reporters than they now take, resulting in more balanced reporting than what the formulaic norm of objectivity produces (Tuchman, 1978).

3. Content analysis. The major task of determining textual meaning should be to identify and describe frames; content analysis informed by a theory of framing would avoid treating all negative or positive terms or utterances as equally salient and influential. Often, coders simply tote up all messages they judge as positive and negative and draw conclusions about the dominant meanings. They neglect to measure the salience of elements in the text, and fail to gauge the relationships of the most salient clusters of messages-the frames-to the audience's schemata. Unguided by a framing paradigm, content analysis may often yield data that misrepresent the media messages that most audience members are actually picking up.

4. Public opinion and normative democratic theory. In Zaller's (1992) account, framing appears to be a central power in the democratic process, for political elites control the framing of issues. These frames can determine just what "public opinion" is-a different frame, according to Zaller, and survey evidence and even voting can indicate a different public opinion. His theory, along with that of Kahneman and Tversky, seems to raise radical doubts about democracy itself. If by shaping frames elites can determine the major manifestations of "true" public opinion that are available to government (via polls or voting), what can true public opinion be? How can even sincere democratic representatives respond correctly to public opinion when empirical evidence of it appears to be so malleable, so vulnerable to framing effects?

Say there are three ways to frame an issue and one generates 40 percent approval, the others 50 percent and 60 percent, respectively. Approving the option with 60 percent support is not axiomatically the most democratic response because of the cyclical majority problem (Riker, 1986), which makes majority rule among several complex options mathematically impossible. Just as important, attempting to determine which of the differently framed opinions is the closest to the public's "real" sentiments appears futile, because it would require agreement among contending elites and citizens on which frame was most accurate, fair, complete, and so forth. A framing paradigm can illuminate, if not solve, such central puzzles in normative democratic theory.

Indeed, the concept of framing is important enough in the many fields of inquiry that use it to merit a book-length essay. The present effort, constrained by space limitations, offers not the definitive word on frames but 
a preliminary contribution. Equally important, this article exemplifies how the field of communication might develop from its wide ambit and eclectic approaches a core of knowledge that could translate into research paradigms contributing to social theory in the largest sense.

\section{References}

Budd, M., Entman, R. M., \& Steinman, C. (1990). The affirmative character of U.S. cultural studies. Critical Studies in Mass Communication, 7, 169-184.

Edelman, M. J. (1993). Contestable categories and public opinion. Political Communication, 10(3), 231-242.

Entman, R. M. (1989). Democracy without citizens: Media and the decay of American politics. New York: Oxford University Press.

Entman, R. M., \& Page, B. I. (in press). The news before the storm: The Iraq war debate and the limits to media independence. In W. L. Bennett \& D. L. Paletz (Eds.), Just deserts: The news media, U.S. foreign policy, and the Gulf War. Chicago: University of Chicago Press.

Entman, R. M., \& Rojecki, A. (1993). Freezing out the public: Elite and media framing of the U.S. anti-nuclear movement. Political Communication, 10(2), 151-167.

Fiske, J. (1987). Television culture. New York: Routledge.

Fiske, S. T., \& Taylor, S. E. (1991). Social cognition. New York: McGraw-Hill.

Gamson, W. (1992). Talking politics. New York: Cambridge University Press.

Goffman, E. (1974). Frame analysis. New York: Free Press.

Graber, D.A. (1988). Processing the news: How people tame the information tide (2nd ed.). New York: Longman.

Iyengar, S. (1991). Is anyone responsible? Chicago: University of Chicago Press.

Kahneman, D., \& Tversky, A. (1984). Choice, values, and frames. American Psychologist, 39, 341-350.

Pan, Z., \& Kosicki, G. M. (1993). Framing analysis: An approach to news discourse. Political Communication, 10(1), 55-76.

Riker, W. H. (1986). The art of political manipulation. New Haven: Yale University Press.

Sniderman, P. M., Brody, R. A., \& Tetlock, P. E. (1991). Reasoning and choice: Explorations in political psychology. Cambridge, England: Cambridge University Press.

Snow, D. A., \& Benford, R. D. (1988). Ideology, frame resonance, and participation mobilization. International Social Movement Research, 1, 197-217.

Tuchman, G. (1978). Making news. New York: Free Press.

White, H. (1987). The content of the form. Baltimore, MD: Johns Hopkins University Press.

Zaller, J. R. (1992). The nature and origins of mass opinion. New York: Cambridge University Press. 